\title{
THE INFORMATION SYSTEMS PROFESSION: \\ MYTH OR REALITY?
}

\author{
by \\ Wanda J. Orlikowski \\ and \\ Jack J. Baroudi \\ Information Systems Area \\ New York University \\ 624 Tisch Hall \\ New York, NY 10003
}

\begin{abstract}
April 1988
Center for Research on Information Systems

Information Systems Area

Graduate School of Business Administration

New York University
\end{abstract}

Working Paper Series

CRIS \#180

GBA \#88-32

Note: This paper is forthcoming in Office: Technology 8 People 
The Information Systems Profession:

Myth or Reality?

\begin{abstract}
Much of the prior research into information systems (IS) workers has assumed that they are professionals. In this paper we examine the characteristics of IS workers, IS work and the IS workplace, and suggest that this perspective is mistaken. Drawing on the sociological theory of professions as a reference discipline we contend that IS professionalism is an inappropriate categorization, and that such a portrayal limits our understanding of IS workers and their work.

We argue in this paper that a more faithful and potentially useful characterization is to view IS workers as members of an occupational group. Within this perspective, an understanding of the occupational culture, context and history of IS workers is essential to an understanding of the IS occupation. We examine and challenge some common myths regarding IS work, technology and the IS workplace. We conclude by making some recommendations for future research are provided, which should enhance our understanding of IS workers as members of an occupation.
\end{abstract}




\section{Table of Contents}

1. INTRODUCTION

1.1. The Need for IS Occupational Research

2. IS PROFESSIONALISM

2.1. Concept of a Profession

2.2. IS Workers as Professionals?

2.3. Why IS Workers Are Not Professionals 10

3. STUDYING IS AS AN OCCUPATION 15

3.1. Issues Raised by the Occupational Paradigm $\quad 15$

3.2. Directions for Research into the IS Occupation 17

$\begin{array}{ll}\text { 3.2.1. Technology of IS Work } & 17\end{array}$

3.2.2. Deskilling/Reskilling 18

3.2.3. Discrimination 19

3.2.4. Unionization 20

4. CONCLUSIONS 


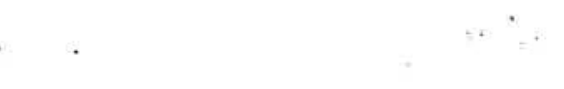





\section{INTRODUCTION}

This paper is concerned with motivating research into the information systems (IS) occupation. This occupation is not only one of the fastest growing sectors in the U.S., but it is also assuming substantial importance in the emerging "information age". Today organizations and many forms of social and political institutions are becoming increasingly reliant on information technology and as a consequence, on the men and women who design, implement, operate and manage such technology. Yet there is little comprehensive or systematic understanding of IS work and IS workers.

\subsection{The Need for IS Occupational Research}

Research into the IS occupation is crucial for several reasons. First, the history of the IS occupation has been one of quick, intense and explosive growth over the last thirty years. Today IS workers constitute a substantial occupational sector (comprising over $1 \%$ of the U.S. labor force [1]) whose growth rate is expected to increase. Projections suggest that by the end of this decade there will be over three million IS workers in the United States [22]. More than the sheer numeric significance of this occupation, which on its own requires systematic investigation, it further demands our attention for the increasing importance being vested in IS skills within our technological society. Perhaps most important is the influence which members of the IS occupation exert on the activities, consciousness and organizational practices of other workers. It has long been noted $[9,10,40]$ that computer-based systems can significantly change the nature of work, the means by which people perform their jobs, the skills necessary to do the work, and the frameworks with which people approach their work $[2,56]$. In order to understand how IS workers create and shape the realities of the countless workers who must use the systems developed, operated and maintained by IS workers, it is important to understand the IS occupation and its workers. For this, we need to study the history, role and status of IS workers in organizations, the institutionalized organization and power of the IS occupation, as well as the knowledge, education, socialization, career orientations, world views and life interests of IS workers. 
We suggest that to adequately undertake such study, more appropriate theoretical frameworks are necessary to guide our view of IS workers. MIS research of IS personnel has uncritically assumed that they constitute a group of professionals $[4,5,6,12,24,37,38]$ without fully realizing the implications behind such a categorization. Research of IS workers, working from the implicit premise of professionalism has neglected important occupational issues that directly impinge on IS workers and relations in the IS workplace. Likewise and reciprocally, there is a pervasive characterization of IS workers as professionals among IS practitioners and the popular trade press, with little if any consideration of the applicability or consequences of such labelling. There is hence a presumption of professionalism in the development of managerial policies concerning the organization of IS work which results in a biased attitude among and towards IS workers. Clearly the findings of research and the policies and practices of business reinforce each other; yet we believe that both are propogating myths about IS work. As will be explained below, we do not believe that the categorization of IS workers as professionals is useful or accurate, but instead that it obscures our understanding of the IS occupation. At worst it serves as an ideology that reinforces stereotypical patterns of work, control and social relations.

The following section briefly examines prior research into the professions. We then provide a critical appraisal of the IS occupation to determine whether or not it can legitimately be said to constitute a profession. ${ }^{1}$. In section three we propose a research framework for studying the IS occupation. We discuss the alternative research issues that arise when we consider workers in occupational terms, and provide some recommendations for future IS occupational research.

\footnotetext{
${ }^{1}$ Our focus on IS workers in this paper does not include data entry workers as they are primarily users of information technology and not designers, builders, or operators of the technology.
} 


\section{IS PROFESSIONALISM}

In this section we explore the concept of professionalism and how it does or does not apply to IS work. Based on a understanding of professions drawn from the sociology of professions literature, we determine the professional status of the IS occupation by examining the history and origins of IS work, the current status of IS knowledge and work, and the relations of IS workers to other organizational and occupational groups.

\subsection{Concept of a Profession}

There is much ambiguity and ambivalence surrounding the use of the term profession, and it has been associated with a range of values, usages, and research interests over time. Early studies in the sociology of professions $[11,13,43]$ attempted to define what a profession is, establish the importance of the professions to the contemporary society, and to determine the means by which new professions emerged and became established. This latter research developed into an extensive interest in the process of professionalization [54] whereby occupations sought to raise their status in society. ${ }^{2}$ Researchers examined the means by which the emerging professions attempted to emulate the traditional professions of law, medicine and divinity, by defining specialized skills and training, forming professional associations, setting minimum fees, developing a code of ethics, and instituting peer control over practice.

Over time however, this focus on the process of professionalization developed into an examination of the attributes of a profession, and the determination of whether certain occupations were professions or not [49]. The sociology of professions became the search for the ideal criteria of professionalism such as: a service ideal, consultation with clients, community as opposed to self-interest, involvement in the occupational culture and its associations, generalist education in accredited university programs, support for the advancement of knowledge in the field, commitment to a code of ethics and the illegitimacy of any occupational control not administered by professional peers

\footnotetext{
${ }^{2}$ By professionalization, we mean the process by which producers of specialized services seek to constitute and control a market for their expertise [36, p.xvi].
} 
[46, pp.62-63]. This represents a shift that Roth [49, p.17] suggests focuses not on the process of professionalization, but on its products. He examines eight different attribute lists, finding little overlap among them, and assails this "scorecard" orientation for being "... contaminated with the ideology and hopes of professional groups rather than an independent assessment of what they achieve." More recently researchers have begun to suggest the possibility that an antithetical process to professionalization - the "deprofessionalization" of established professions - may be emerging as result of increased bureaucratization and technological innovation in our advanced industrial society $[30,31,36]$.

In the current sociological literature, professions are typically characterized as a special case of occupational groups that have attained peculiar status and power within society, which they confer on their members [16, p.213]. A number of contemporary approaches to theorizing about the professions have been developed [17], based on (a) the characteristic features of a profession, (b) the power of the profession over clients, policymakers, educators and the public, and (c) the process by which professional work is conducted. Forsyth and Danisiewicz [17] adopt the view that power is the central element of professions, and support Freidson's [18] notion of professional autonomy as a useful index by which to explore the relative "professional status" of various occupations. They suggest that professional autonomy is manifested in two forms: control over the client and autonomy from the employing organization. More recently Freidson [19] has expanded this notion of professional power, focusing on a profession's organizational features and its exercise of authority via its political and economic ties as well as its educational institutions.

Following Freidson $[19, \mathrm{p} .41]$ we adopt the category of a profession in this paper, to refer to (a) a group whose members gain a living while serving as agents of formal knowledge, which implies that the members are credentialed on the basis of higher education, and (b) a set of institutions and practices (developed and maintained by the group) that operate in the political economy to create and sustain labor market shelters for their members, e.g. through accreditation, licensing, lobbying, policy making, 
standard setting and so on [19, p.59]. Professionalism here is viewed as "... one of the most fundamental forms of legitimacy and political control which is sought in the contemporary organization of work" [16, p.218]. We will use this understanding of professions to guide our analysis of IS work and the various claims made for and against IS professionalism.

\subsection{IS Workers as Professionals?}

There is a presumption in the IS research literature that IS workers comprise a profession [4, 5, 6, 12, 24, 37]. For example, Markus \& Bjorn-Andersen [38] refer to "IS Professionals" as individuals who "consult with users", broadly applying Freidson's [18] definition of the consulting professions to include such diverse workers as "... systems analysts, designers, managers, and vendor marketing and product development personnel" [38, p.499]. While we accept Freidson's [1970] distinction between the consulting and the learned professions, we question the appropriateness of labeling IS workers as members of a consulting profession. ${ }^{3}$ Firstly, as we elaborate later, such a broad categorization of different IS tasks and responsibilites is problematic, and secondly, the relationship between IS workers and users is largely circumscribed in terms of its purpose and outcomes, unlike the situation with true consulting professionals (such as medical and law practitioners) who typically have substantial autonomy from their organization and over their clients.

The attribution of the title "professional" to IS staff by management in general, must be carefully scrutinized. Goldner and Ritti [23] found that managers used the professional label to characterize their engineering staff in order to obscure the fact that the engineers had very little career mobility within the organization. Thus the label professional was used to provide the illusion of status and to appease a technologically necessary workforce, without having to offer them real career opportunities. We suspect, although there have been no systematic studies of this issue, that a similar use of professionalistic rhetoric is prevalent in the IS workplace.

\footnotetext{
3 "Consulting" professions are seen to be engaged in solving practical problems for clients (e.g. physicians and lawyers), while the "learned" professions are engaged in collaborating with colleagues (e.g. scholars and researchers).
} 
In asserting that the IS occupation does not constitute a profession, it must be clearly understood that we are making a distinction between occupational professionalism and individual professionalism, as explicated by Ritzer [46, pp.61-62]. Individual professionalism addresses the specific attitudes, values, and utilization of skills and discretion expressed by an individual in the conduct of his or her work and is independent of the societal position of his or her particular occupation. ${ }^{4}$ We are concerned here with occupational professionalism, or in Freidson's [18, p.185] term, the "professional status" of an occupation which addresses the status of the total occupation vis-a-vis the legal or socially recognized definitions of professional work. It should be noted [18, p.70], that individual professionalism may, and frequently does, exist independently of occupational professionalism. We argue that the IS occupation does not have formal professional status in society today, nor do we believe that it warrants such categorization, as an examination of its constituency, activities, training, occupational structure, affiliations and patterns of work and control, will reveal. This however, does not mean that strong forces do not exist within factions of the IS community that are striving to achieve the professionalization of IS work.

The history of the IS occupation is filled with attempts by certain factions of the IS practitioner community to obtain government recognition of the putative professional status of systems analysts and programmers. None of these have been successful. In March 1971 the U.S. Court of Appeals ruled that "...programmers and analysts were better described as 'technical' rather than 'professional' employees ...[as their work]... did not require a professional measure of skill, knowledge and independent exercise of judgement" [21]. In December 1971 the Labor Department decided that operators, programmers and systems analysts are covered by the Fair Labor Standards Act, and hence entitled to overtime pay. The summary read "... there is too much variation in employment standards and academic requirements" of such workers to conclude that they are "...part of a 'true' profession" [52]. Both decisions were upheld by a 1976 federal court decision which found programmers to be ineligible for classification as

\footnotetext{
${ }^{4}$ For example, a specific taxi-driver can be a professional in his or her work just as much as a lawyer can; on the other hand, both can display nonprofessional conduct in their work.
} 
professional, executive or administrative employees [26]. Likewise Freidson $[19$, p.60] suggests that computer programmers are not professionals as their working does not depend on the possession of specific credentials based on higher education.

Notwithstanding these legal interpretations, there has been a consistent claim from the leadership of the Association for Computing Machinery (ACM) that IS workers do comprise a profession and so require certification and governmental licensing [39]. To assist in meeting this goal, eight IS associations have incorporated two bodies: the Computer Foundation and the Institute for Certification of Computer Professionals; the former to garner financial and political support for the professionalization campaign, and the latter to administer examinations and issue Certificates in Computer Programming (CCP) for IS workers (to augment the existing Certificate in Data Processing (CDP), aimed at IS managers). Such attempts as well as the attempts by the ACM to establish guidelines for educational competence in IS through their publication of self-assessment tests and curricula guidelines for university courses in computer science and IS, may be seen to be strategies aimed at establishing the professional status of the IS occupation. In this, the institutional bodies of the IS occupation are actively engaged in constructing social reality, both at the symbolic and economic/political levels [28].

The ideological undertones of such professionalization projects should not be ignored. Larson [36] suggests that endeavors by certain occupations to win professional status are attempts to manipulate the market for services via controlling the supply of expertise, increasing the demand for licensed and hence scarce skills, obtaining and sustaining a monopoly over expert knowledge, establishing a protected niche or labor market shelter, and gaining prestige, status, influence and material benefits in organizations and throughout society. These implicit motives are invariably obscured by the ideology surrounding the role of professional workers, such as implicit in the ideal criteria of professions. As discussed earlier, these trappings of professionalism have been traditionally used in the sociology of the professions as criteria by which occupations may be classified as professions. Esland [16, p.218] notes that this "trait" or 
"inventory" approach has more to do with supporting the professions' own conception of themselves, than with identifying some "essential qualities" of professional status.

In the following section we will examine the characteristics of the IS occupation to determine the extent to which it can be categorized as a profession. To do this we need some means by which professional status can be attributed to an occupation. As we have seen, most analysts of the professionsadopt an inventory list of ideal-typical professional traits, and then measure the particular occupation under study against this $[13,25,46]$. There is much debate about the adequacy of such an approach $[16,18,36]$, as well as disagreement about which criteria are most appropriate $[27,46]$. Recognizing the problems associated with adopting such trait analysis we will follow Freidson [18], who asserts that the major consistent criterion for distinguishing professions from other occupations is their position of legitimate control over their work. He suggests that many other aspects of professional status stem from this primary dimension, such as control over knowledge, training, and other occupations. He notes further, that a secondary dimension of professionalism is control over the social and economic terms of work.

In our investigation of the professional status of the IS occupation we will draw on Freidson's [18] insights, and examine the following elements:

1. Control over the technical terms of work: What is essential here is control over the determination and evaluation of the knowledge used in the work. Such control is also referred to as technical autonomy.

2. Control over the education and training process: Here common, uniform training by authorized establishments is required by all practitioners, to ensure control over access and entry into the profession.

3. Freedom from competition with, and freedom from the regulation of, other occupations.

4. Control over other occupations (para-professionals), as well as control over clientele through the definition and treatment of their problems (as distinct from conformance to their needs). 


\subsection{Why IS Workers Are Not Professionals}

While we examine IS workers in terms of the above four criteria, there is an even more serious consideration which complicates the notion of an IS profession, that is, the stratification of duties and specializations present in today's IS workplace [33, 37, 53]. By themselves, these are representative of too large a span of work discretion, responsibility, training and skills to warrant talk of IS work as a profession. The IS occupation, unlike professions is vertically stratified, as well as laterally differentiated into numerous technical and administrative specialities. IS work has a great range of skills, tasks, expectations, responsibilities and promotional opportunities that exist at different hierarchical levels as well as technical and functional specialities [37, p.150]. Turner \& Baroudi [53] demonstrate the multi-faceted nature of the IS occupation by delineating ten different sets of jobs within it. Thus the IS occupation is not uniform, neither in terms of the range of tasks performed nor the skills, training and loyalties of the workers. In fact it might be argued that the IS occupation consists of an amalgam of various sectors from the labor market (operators, clerical workers, technical experts, business consultants, managers) rather than a single labor market sector in itself.

However, even if we ignore the above problem of stratification, the IS workforce does not score highly on any of the criteria of professionalism, as we discuss below.

1. Technical Autonomy: Freidson [18, p.82] argues that the only valid criterion for distinguishing professions is their position of legitimate, self-regulating autonomy, that is, professionals are deliberately given the right, officially by the state and implicitly by the public, to control their own work (to define, perform and evaluate it). Historically the IS occupation arose out of the post-war, scientific-military complex, and so IS work has never been an independent, free-standing occupation. Unlike traditional craftspeople or professionals such as physicians, lawyers or engineers (who had entrepreneural origins), the autonomy of IS workers was circumscribed from the first. They never had powers of self-evaluation or self-regulation, and as with most occupations, IS workers were employed from the moment of their emergence [19, p.122]. The policies and goals of their work as well as the problems they addressed were, and are, typically set by their employers. 
Most established professionals such as physicians, lawyers, and architects work in professional organizations where peer evaluation and individual autonomy are important aspects of their work. By and large, IS workers do not work in "professional" IS organizations. $^{5}$ The typical IS worker is employed in a non-IS, heteronomous organization and is subject to a bureaucratic philosophy and varying degrees of IS and non-IS managerial practices. Established professionals employed in bureaucratic organizations bring with them a set of externally (professionally) derived standards by which they guide their own performance [29, 44]. Such socialized behavior and shared, patterned norms are not evident among IS workers. The majority of IS workers are mainly concerned with applying their specific, technical expertise in relatively welldefined situations. What is done, why it is done, and how it is executed is not ordinarily determined by the IS workers themselves, or by some independent professionally-defined "IS practices and procedures". This is not to say that IS workers do not employ any work discretion, or do not adopt unique responses to their task contingencies. But these typically are circumscribed and controlled by bureaucratically imposed tools and techniques as well as predefined criteria of performance and quality. Such workers are accountable to their supervisors, and unlike autonomous professionals, they have no power to set the parameters of their work, and do not possess a license (either literally or figuratively) to venture beyond the bounds of their prescribed organizational job descriptions. There is no professional/peer control, and IS workers (including independent contractors and consultants) are not held personally and legally liable for defects in their products or services as individual accountants, certified surveyors, licensed architects, lawyers and medical practitioners are.

2. Control over Education and Training: There is no established "monopoly of competence" within the IS occupation. Control of the IS educational process is incomplete and there is no effective control over entry into the occupation. The training of computer workers is varied, nonstandardized, typically piecemeal, and

\footnotetext{
${ }^{5} \mathrm{~A}$ few do, such as employees of software companies and IS consulting firms, and these employees probably have more control over their work procedures and display greater client orientation than IS workers employed by non-IS organizations.
} 
constantly changing with changes in hardware and software. It ranges from on-the-job experience, vendor training, high-school and community college diplomas to business, computer science and engineering degrees. Experience with particular hardware configurations and software products is inevitable and highly valued where such skills are scarce and the hardware/software popular. Hence technical IS workers specialize beyond the general tasks of operating or programming, to operating or programming with specific tools, technologies and products [34].

The IS occupation clearly does not have control over its knowledge base unlike professional groups such as doctors, lawyers, and accountants. Three major forces mitigate against the establishment of such control. First, computer knowledge and techniques are produced by a diversity of sources: computer science, business administration, management science, cognitive psychology, engineering, and large numbers of amateur 'garage' enthusiasts. Second, the IS knowledge base and accompanying skills are not predominantly theoretical or abstract [34, p.38]. On the contrary, the majority are highly practical, specialized, unique to a particular piece of hardware or software and typically nontransferable across IS installations. They are also volatile, rapidly made obsolete by the frequent and dramatic changes in information technology $[33,34]$. Third, there has been and continues to be, a mass proliferation of computers throughout society and organizations; the spread of microcomputers in homes, schools and offices has distributed computer technology and computer literacy to many non-IS practitioners.

3. Control by other Occupations: IS workers are not free from regulation by other occupations; in particular they have no autonomy from their employing organizations. The IS occupational identity is intimately coupled to the context and contingencies of large, modern bureaucracies. References to the craft-based origins of IS work $[26,35,44]$ are romanticized and ideological. Unlike established professionals whose relationships to the public and organizations have assumed a relatively predictable pattern over the last thirty years, the status and roles of IS workers with regards to organizations have been highly variable and uncertain [42]. In the past, the work of IS 
employees within organizations was located and organized within a formal, distinct structural entity: the IS group or unit. Initially subsumed under the accounting or controller's department in the sixties, the IS unit gained independent jurisdiction over its affairs, and during the seventies rose in hierarchical stature within many organizations. Today we see the notion of an independent, self-sufficient and typically monopolistic IS unit [14] blurring rapidly, both internally via the spill-over of application development and operations to user departments, and externally with the increased popularity of software package vendors, contract programmers and IS consultants. The IS unit is conventionally portrayed as providing technical and administrative support for the basic operations of the firm. However this role too is changing dramatically as information technology is becoming a valuable commodity which is sold directly as a primary service to customers (e.g. electronic funds transfer, home shopping, electronic information access), and used strategically in innovative ventures to improve the competitive position of organizations [32]. In this context, IS work is intimately related to the particular strategic orientation of the organizations, and its contours are shaped by the demands of the dominant organizational coalitions.

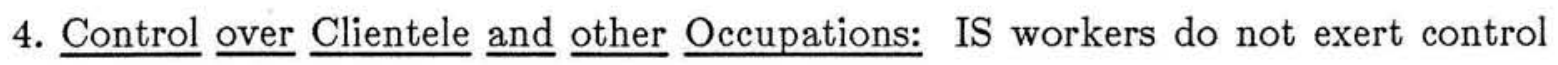
over occupations in the same way that medical practitioners exert influence over nurses and medical technologists. The work of these latter occupations is clearly defined, evaluated and dominated by the medical profession. IS workers (including here operators, programmers, analysts and the various technical specializations) have an occupational hierarchy where certain groups such as analysts have greater status and authority than others such as programmers and operators, but this sort of control of work contingencies is not exerted over other occupations. While much has been written about the potential for IS units to spearhead the strategic thrust of corporations [32], and so exert influence over other occupations in the organization, there is little actual evidence of such a role in corporate practice.

Further, IS workers cannot be generally characterized as having authority over their clients (in this case the users). IS work is largely commissioned and sponsored by 
user managers (perhaps by a formal steering committee), and in most organizations IS workers respond to the needs of users for new services and systems or extensions and modifications to existing systems. There is some ambiguity here though, in that IS workers do often exert technical authority over the users, and can be seen to define users' problems in particular ways and select design solutions that come to shape users' lives [41]. However the distinction between this sort of influence and that exercised by established consulting professions is significant. In the latter case the body of knowledge and techniques deployed by the professionals is distinct from the particular problems their clients bring with them. Here the professional's practice is largely independent of the client base he or she serves. The clients' problems are diagnosed and treated in accordance with some standard, externally legitimated procedure. IS work on the contrary, is intimately coupled to the particular set of users' needs. Here the problem definition and the solution procedures are specifically tailored to the particular installation, particular technology type and particular user information requirements. IS workers do not work from some independent knowledge which they deploy to define their users' problems. Their role in the organization requires them to specialize their procedures to conform to a narrow set of problems and needs of their clients. IS workers' diagnosis and understanding of user problems and needs is contextual, constrained by their involvement in a shared organizational culture, by organizationally defined goals, priorities and values, by the history of prior IS-user relations, existing technology, and IS department procedures.

In addition, the extensive infiltration of micros into all organization levels has weakened the exclusive control that IS personnel have exerted over the computer resources and their prerogative over IS work. The growth of end-user computing has been dramatic over the past few years, and forecasts predict substantial increases in this area $[8,47]$. More and more users are beginning to meet their own information requirement demands, with and without support from IS workers. Emphasis on user participation and prototyping strategies as well as the increased reliance being placed on information technology by organizations today suggest that users are likely to increase their authority vis-a-vis IS workers in deciding how, why and when information technology is deployed. 
In the following section we argue that imposing a characterization of "professionals" on IS workers is limiting and that more useful understanding will come from analyzing them in occupational as opposed to professional terms. The notion of an occupation is defined and its analytic value for research into IS work and IS workers is explored.

\section{STUDYING IS AS AN OCCUPATION}

Given the inappropriateness of describing IS workers as professionals, we suggest that it would be more instructive for researchers to adopt the notion of IS workers as an occupational group. Even though professions are a special kind of occupation, deliberately adopting an occupational perspective (as opposed to implicitly adopting a professional one) should focus our attention on issues different from those pertinent to the professions, and force us to question some of our taken for granted assumptions about IS work. For example, adopting an occupational frame of reference recognizes the necessity of distinguishing within the IS occupation among the various lateral specialities and many hierarchical levels, of examining the variety of training programs available to IS workers, of investigating discrimination patterns, union participation rates and actions, changes in skills, technical autonomy, interaction with management, and subordinate and dominant relations with other occupations. Categorizing IS work in occupational terms suggests an entire array of issues and questions, many of which are yet to be explored. In the following sections we outline a number of these important issues.

\subsection{Issues Raised by the Occupational Paradigm}

In defining occupations, Salaman [50, p.35] notes "An occupation involves more than just a work title ... Occupation refers to identity-giving work; work consisting of an acknowledged and recognized body of skills, activities and knowledge which are regarded as having significance for the identity and values of those concerned." Membership in an occupation has implications for identity, attitudes, interests, colleagueship, collective action, power, status and work consciousness. We subscribe to 
Freidson's [19, pp.35-36] notion that an occupational group needs to be investigated phenomenologically and historically. Such an approach avoids attempting to determine what the occupation is in an absolute sense, but rather generates research into how society identifies members of the occupational group, how the occupation creates and recreates its identity and status through the activity of its members, and what the consequences are for the way the members perceive themselves, apply their knowledge and perform their work.

In exploring occupations it is important to realize that characteristics of the occupational sector and its labor market may not be external, but heavily influenced by the social and political processes within the occupation, as it consolidates power, wins organizational legitimacy and social prestige, and uses these to its advantage, e.g. by expanding occupational boundaries, establishing quality standards, and so on [7]. Research into occupational groups tends to focus on the common interests and shared values of members, as well as relations across occupations. It is also important, however, to recognize and analyze division and conflict within an occupation, where members "... may very well be in competition with each other for economic and symbolic rewards rather than joined together in a common cause" [19, p.56]. An excellent example of intra-occupational power struggles is presented by Pettigrew's [45] longitudinal study of the competition between burgeoning systems analysts and established computer programmers to gain organizational influence and prestige.

Studies in the sociology of occupations have found that workers' experiences of the meaning of work, their orientations to work and the organization, and their relationships with managers and other workers are heavily influenced by the collective values transmitted through initiation into and continued membership within a distinct occupation. In studies of any occupation we are interested in determining how workers are trained, recruited, socialized; what the barriers to entry are; what the career options and patterns for workers in the occupation are (within one organization or across many organizations); the nature and practice of discrimination within the occupation, as well as the opportunities for advancement and mobility. Occupational researchers are also 
concerned with the type of tasks and typical problems, constraints and rewards of the various jobs; the nature, characteristics and contingencies of the variety of workplaces; the modes of interaction with and dependence on other workers and clients; the structural features of the occupation in terms of status, collective power, associations, unions, legislation and labor market shelters. Such knowledge helps to paint a more complete picture of an occupation and its members.

\subsection{Directions for Research into the IS Occupation}

In this section we outline four specific directions that future research into the IS occupation needs to focus on: the technology of IS work, the deskilling and reskilling of IS work and/or workers, discrimination among IS workers, and IS unionization. We focus on these issues, as they more than any of the others, have been ignored by our uncritical assumption that IS workers are professionals. Yet these four research areas have potentially serious influences on the nature and status of the IS occupation.

\subsubsection{Technology of IS Work}

A critical dimension of any workplace is the technology deployed by the workers in the execution of their tasks. To avoid taking simplistic perspectives of the information technology employed by IS workers, researchers need to carefully delineate its complex and multidimensional features. Cognizance of the highly volatile nature of information technology and distinctions among the various hardware and software configurations is required. Concomitantly future research should recognize and explore the implications for IS workers of:

- the emergence of integrated application development tools which are computer-based aids that assist programmers and designers in the development of information systems;

- the advent of a growing, computer-literate end-user community and its influence on and participation in application development;

- the increased emphasis on developing information systems as "competitive weapons" and the escalating size of the information systems budget;

- the growth in the number of organizations employing information technology 
as their core technology and producing information products and services as primary commodities, with a resultant increase in organizational dependence on information systems use and development.

Future research exploring the relationship between IS workers and information technology must not fall into the trap of technological or managerial determinism. IS occupational research needs to recognize the ability and tendency of agents to counter and change (individually or collectively) the effects of technology in their worklives.

\subsubsection{Deskilling/Reskilling}

The history of occupations are riddled with accounts of changes in skill, particularly as over time the nature of work, and the means of performing work, have changed dramatically. Within the IS sector we are particularly concerned with changes in skills due to information technology, and how these changes affect each of the subcategories/job categories of the occupation. Of critical significance here, is the direction of the skill changes, and whether these changes affect the skills of individuals or the skill requirements of jobs. Individual deskilling is concerned with the extent to which the skills a person possesses (such as knowledge of COBOL) have become obsolete. Job deskilling is the extent to which the skills necessary for a job become downgraded (so as to make knowledge of JCL no longer necessary for programming because new operating systems have take over these functions). Reskilling or upskilling of jobs within occupations is also possible, for example, when knowledge of DB2 becomes necessary for programming positions. It must be borne in mind, however that the deskilling/reskilling of a job may, but need not deskill/reskill the particular job incumbent.

Within an occupation shifts in job skill requirements and individual skills tend to be interdependent. It is quite possible for new technologies or skill requirements to greatly deskill individual IS workers and jeopardize their jobs. While technological changes may also be found in the professions, the possibility of an individual professional having his or her job security or status reduced, is mitigated by the extent to which the professional association decides whether the change is "legitimate" or not, 
and by the professionals being the agents that implement the change and make them available to the public. Such institutional protection is not afforded members of occupations and is not available to IS workers. Under these circumstances, studies into the shifting employment patterns of different IS job categories and the technological deskilling/reskilling of IS work and workers becomes critical. For example, the development and introduction of the microcomputer into the organization has opened entire new categories of jobs [48] which in some companies are challenging the dominance and security of the centralized IS unit and the job security of its members.

We propose however, that researchers focus less on broad generalizations about the deskilling or reskilling potential of information technology, and concentrate rather on the realities experienced by IS workers in their everyday work. This requires longitudinal and contextual research that is sensitive to variations in time, environment, technology, tasks, and skills. Further we should not expect monolithic, uni-directional changes, rather we should expect many unanticipated consequences, and allow for both deskilling and reskilling effects to occur in the same job simulataneously [3]. In particular, the very nature of different IS skills needs to be explored and defined. Little research has been conducted that attempts to understand what the socially recognized set of skills employed by IS workers are, what elements constitute these skills, and how these skills are acquired, sustained and changed within IS practice.

\subsubsection{Discrimination}

A particularly important occupational issue that has been neglected in studies and discussions of the IS workplace is that of minority discrimination. The prevailing ideology is that IS work is (fortunately) bereft of the problems of discrimination. Examination of the US Census data over the last two decades however, reveals that stereotypical attitudes about appropriate jobs for females prevail in the IS occupation, as they do in most other occupations. Weber and Gilchrist examined census data for 1970 and found for the data processing sector that "... the available data suggest that women are not receiving equal pay for equal work and may not be sharing equally in the opportunities for advancement" [55, p.416]. An examination of more recent census 
figures indicate that these problems still persist. According to the 1980 census data of the individuals employed as systems analysts and computer scientists, 78 percent were male and 22 percent female. 70 percent of all programmers were male while only 30 percent were female. A probability survey of computer software specialists in the Boston S.M.S.A. conducted by Dubnoff and Kraft found that "Females are overrepresented in maintenance and documentation, the two lowest paid specializations [15, p.6]. Although they [women] perform supervisory tasks in proportion to their overall representation in the occupation, they are clearly excluded from higher paid managerial functions such as planning the direction of a department, controlling budgets, and evaluating hardware and software for purchase. In short, women are more likely to be supervisors rather than executives." This was true even when controlling for differences in education and experience. The dominant belief among researchers and practitioners that IS work, unlike most white collar occupations, does not practice gender discrimination is a myth that needs far more attention from researchers.

\subsubsection{Unionization}

The issue of IS unionization has been the cause of much debate in the IS workplace, but it seems to have been ignored by MIS researchers, probably due, to the predominant view of IS workers as professionals. Large numbers of IS workers outside of the U.S. however, have been unionized. Friedman et al. [20, pp.93-94] report that union participation rates among IS workers in Europe are $53 \%$ on average, as compared to the U.S. where only $13 \%$ of private and public sector IS workers are unionized. Kraft [35], Greenbaum [26] and Garner [21] charge that managers have deliberately undertaken to portray IS workers as professionals in order to prevent them from organizing and so posing a threat to the short-term profitability and long-term survival of the firm. Sterling [51] describes some interesting cases of the attempts by management to exclude IS workers from union participation by employing professional engineers to do IS work. IS workers, themselves, have also discouraged IS unionization and engendered a professional self-perception. The self-perception of many IS workers about their "unique skills", their particular status and expertise, and their elitist attitude [26, p.104] sets them apart from assembly-line or clerical workers and provides 
fertile ground for IS association leaders to sow the seeds of a professional mentality. This is an illusion that IS occupational research should not reinforce.

Clearly an important element in any analysis of the IS occupation which relates to the issue of IS unionization must be the deployment of IS workers by managers to counter the collective resistance of the other workers in the organization/industry. Sterling's [51] account of the FAA during the 1981 air traffic controllers' strike is illustrative here. From this perspective IS workers can be seen to provide a substantial bargaining advantage to the side they support. To date, IS workers have usually served managerial interests, in direct opposition to the efforts of the striking labor force.

Research into these four topics will help to provide a more comprehensive understanding of the IS occupation, as well as help to dispel some of the professionalistic bias inherent in current conceptualizations of IS work. While we have discussed only four themes in occupational research here, these are merely suggestive and clearly not exhaustive. We do not wish to narrow the focus of researchers into the IS occupation, and we urge the examination of a broader array of occupational issues as outlined in section 3.1.

\section{CONCLUSIONS}

It is important that IS occupational researchers adopt a historical approach which links the present state of affairs to the past and the future. This is particularly relevant with respect to the IS occupation which, in responding to rapid shifts in the technological environment, is constantly transforming the way work is done and what skills are valued. What the members of this occupation do today may be very different from the kinds of work they did last year and completely different from what they will do next year. If our research takes a static view of the IS occupation our findings may be misleading, as what we find and report may not be relevant for long. Studies of yesterday's mainframe programmer probably do not speak well to today's microcomputer programmer. A critical role of a historical perspective is that it forces us to acknowledge the changing nature of social reality and to recognize that the current 
conditions are but one, time-dependent, and culture-specific way of organizing the IS occupation.

We urge that future researchers root their understanding of the IS occupation within the theoretical precepts of broader occupational research and learn from the wealth of empirical investigations conducted into other occupations. The IS occupation is a rich and diverse tapestry deserving rich and diverse investigations. 


\section{References}

1. Anderson, Ronald E. \& Mortimer, Jeylan T. "Sociology of Compuer Work". Sociology of Work and Occupations 6, 2 (May 1979), 131-138.

2. Attewell, Paul \& Rule, James. "Computing and Organizations: What We Know And What We Don't Know". Communications of the ACM 27, 12 (December 1984), 1184-1192.

3. Attewell, Paul. "The De-skilling Controversy". Work and Occupations, (forthcoming 1987), .

4. Baroudi, Jack J. "The Impact of Role Variables on Information Systems Personnel Work Attitudes and Intentions". MIS Quarterly 9, 4 (December 1985), 341-356.

5. Baroudi, Jack J. \& Ginzberg, Michael J. "Impact of the Technological Environment on Programmer/Analyst Job Outcomes". Communications of the ACM 29, 6 (1986), 546-555.

6. Bartol, Kathryn M. \& Martin, David C. "Managing Information Systems Personnel: A Review of the Literature and Managerial Implications". MIS Quarterly Special Issue (December 1982), 49-70.

7. Begun, James W. "Economic and Sociological Approaches to Professionalism". Work and Occupations 19, 1 (February 1986), 113-129.

8. Benjamin, R.I. "Information Technology in the 1990's: A Long Range Planning Scenario". MIS Quarterly 6 (June 1982), 11-31.

9. Bostrom, Robert P. \& Heinen, Stephen J. "MIS Problems and Failures: A SocioTechnical Perspective - Part I: The Causes". MIS Quarterly 1, 3 (September 1977), 17-32.

10. Bostrom, Robert P. \& Heinen, Stephen J. "MIS Problems and Failures: A SocioTechnical Perspective - Part II: The Application of Socio-Technical Theory". MIS Quarterly 1, 4 (December 1977), 11-28.

11. Carr-Saunders, A.M. \& Wilson, P.A.. The Professions. Clarendon Press, Oxford, 1933.

12. Chesebrough, Pamela H. \& Davis, Gordon B. "Planning a Career Path in Information Systems". Journal of Systems Management 34, 1 (January 1983), 6-13.

13. Cogan, Morris L. "Towards a Definition of Profession". Harvard Educational Review 2S, 1 ( 1953), 33-50.

14. Danziger, James N. "The Skill Bureaucracy and Intraorganizational Control". Sociology of Work and Occupations 6, 2 (May 1979), 204-226. 
15. Dubnoff, Steve \& Kraft, Phillip. Gender Discrimination in the Computer Industry. Unpublished Working Paper, Department of Sociology, SUNY Binghamton, 1986.

16. Esland, Geoff. Professions and Professionalism. In The Politics of Work and Occupations, University of Toronto Press, Toronto, 1980, pp. 213-250.

17. Forsyth, Patrick B. \& Danisiewicz, Thomas J. "Towards a Theory of Professionalization". Work and Occupations 12, 1 (February 1985), 59-76.

18. Freidson, Eliot. Profession of Medicine: A Study of the Sociology of Applied Knowledge. Dodd, Mead \& Co., New York, 1970.

19. Freidson, Eliot. Professional Powers: A Study of the Institutionalization of Formal Knowledge. The University of Chicago Press, Chicago, 1986.

20. Friedman, Andrew et al. "The Challenge of Users and Unions". Datamation (September 1984), 93-100.

21. Garner, L. "Computer Workers as Professionals". Science for the People (November 1974), 28-32.

22. Gilchrist, Bruce et al. "The DP Population Boom". Datamation (May 1983), 100-110.

23. Goldner, Fred H. \& Ritti, R.R. "Professionalization as Career Immobility". The American Journal of Sociology 72 (March 1967), 489-502.

24. Goldstein, D.K. \& Rockart, J.F. "An Examination of Work-Related Correlates of Job Satisfaction in Programmer/Analysts". MIS Quarterly 8, 2 (1984), 103-115.

25. Goode, William J. "Encroachment, Charlatanism, and the Emerging Profession: Psychology, Medicine, and Sociology". American Sociological Review 25, (1960), 902-914.

26. Greenbaum, Joan. In the Name of Efficiency. Temple University Press, Philadelphia, 1979.

27. Hall, Richard. "Professionalization and Bureaucratization". American Sociological Review 39, 1 (February 1968), 92-104.

28. Hall, Richard. "The Social Construction of the Professions: Comment". Sociology of Work and Occupations 6, 1 (February 1979), 124-126.

29. Hall, Richard H.. Organizations: Structure and Process. Prentice-Hall Inc., Englewood Cliffs NJ, 1982.

30. Haug, Marie R. Computer Technology and the Obsolescence of the Concept of Profession. In Haug, Marie R. \& Dofny, Jacques, Ed., Work and Technology, Sage Publications, Beverly Hills, CA., 1977, pp. 215-228. 
31. Heydebrand, Wolf V. "Technarchy and Neo-Corporatism: Toward a Theory of Organizational Change under Advanced Capitalism and Early State Socialism". Current Perpsectives in Social Theory 6 (1985), 71-128.

32. Ives, Blake \& Learmouth, Gerard P. "The Information System As A Competitive Weapon". Communications of the ACM 27, 12 (December 1984).

33. Kling, Rob \& Gerson, Elihu. "The Social Dynamics of Technical Innovation in the Computing World". Symbolic Interaction 1, 1 (Fall 1977), 132-146.

34. Kling, Rob \& Gerson, Elihu. "Patterns of Segmentation and Intersection in the Computing World". Symbolic Interaction 1, 2 (Spring 1978), 24-43.

35. Kraft, Philip. Programmers and Managers: The Routinization of Computer Programming in the United States. Springer-Verlag, New York, 1977.

36. Larson, Magali Sarfatti. The Rise of Professionalism: A Sociological Analysis. University of California Press, Berkeley, CA, 1977.

37. Markus, M. Lynne. Systems in Organizations: Bugs and Features. Pitman Publishers, Boston, 1984.

38. Markus, M. Lynne \& Bjorn-Anderson, Niels. "Power over Users: Its Exercise by System Professionals". Communications of the ACM 30, 6 (June 1987), 498-504.

39. McCracken, Dan. "The Institute for Certification of Computer Professionals: A Call for ACM Action". Communications of the ACM 22, 3 (March 1979), 145-146.

40. Mumford, Enid \& Henshall, Don. Designing Participatively. Manchester Business School, Manchester, England, 1983.

41. Orlikowski, Wanda J. The Cultural Implications of Information Systems Development Methodologies. Working Paper, Information Systems Area, New York University, 1987.

42. Orlikowski, Wanda J. "The DP Occupation: Professionalization or Proletarianization?". Research in The Sociology of Work 4 (1987, forthcoming).

43. Parsons, Talcott. "The Professions and Social Structure". Social Forces 17, (May 1939), 457-467.

44. Perrolle, Judith A. "Intellectual Assembly Lines: The Rationalization of Managerial, Professional, and Technical Work". Computers and the Social Sciences 2 (1986), 111-121.

45. Pettigrew, Andrew M. "Occupational Specialization as an Emergent Process". Sociological Review 21, 2 (1973), 233-278. 
46. Ritzer, George. Professionalism and the Individual. In Freidson, Eliot, Ed., The Professions and their Prospects, 2nd ed., Sage Publications, Beverly Hills, CA., 1973, pp. 59-74.

47. Rockart, J.F. \& Flannery, L.S. "The Management of End-User Computing". Communications of the ACM 26, 10 (October 1983), 776-784.

48. Ahituv, Nic, Baroudi, Jack \& Ronen, Boaz. "The Characteristics of MicroComputer Support Personnel: A Normative View". Human Systems Management, (forthcoming 1988), .

49. Roth, Julius A. "Professionalism: The Sociologist's Decoy". Sociology of Work and Occupations 1, 1 (February 1974), 6-23.

50. Salaman, Graeme. The Sociology of Work: Some themes and issues. In The Politics of Work and Occupations, University of Toronto Press, Toronto, 1980, pp. 1-41.

51. Sterling, Theodore D. "The Emerging Role of White-Collar Computer Workers vis-a-vis Organized Labor". Office: Technology and People (February 1984), 155-165.

52. Titus, James P. "Wage and Hour Laws Specified for Computer Center Employees". Communications of the ACM 15, 2 (February 1972).

53. Turner, Jon \& Baroudi, Jack. "The Management of Information Systems Occupations: A Research Agenda". Computer Personnel 10 (December 1986), 2-10.

54. Vollmer, Howard M. \& Mills, Donald L.. Professionalization. Prentice-Hall Inc., Englewood Cliffs NJ, 1966.

55. Weber, Richard E. \& Gilchrist, Bruce. "Discrimination in the Employment of Women in the Computer Industry". Communications of the ACM 18 (July 1975), 416-418.

56. Zuboff, Shoshanna. "New Worlds of Computer-Mediated Work". Harvard Business Review 60, 5 (September-October 1982), 142-152. 